appointment rests in each case with the research association, and not with this Department."

In the case of the Glass Research Association the State contribution to its funds for the next five years is three-quarters of the total. In view of its relatively large contribution, the State should be able to exercise more than a merely nominal control over the appointment of the director; if it cannot do so, it should take immediate steps to remedy its position.

It is the opinion of the National Union of Scientific Workers that it is the subordination of the scientific worker to the "business man" which has been chiefly responsible in the past for the tardy development of scientific industry in this country. It feels that this appointment negatives the aims outlined by the Department, and that the whole industry will suffer from the consequent neglect of the scientific aspects of glass research work and from the unwillingness of scientific workers to submit to such direction.

We firmly believe that the matter is one of the first importance, and that the result of our representation in this matter, not only with a commercial organisation, but also with the Department charged with the care of scientific interests in the country, may determine the relations of science and industry for many years to come.

A. G. Church,

I9 Tothill Street, Westminster;

S.W.I, March 6.

On Langmuir's Theory of Atoms.

THE great objection to Langmuir's theory of atomic structure is the difficulty of accepting his hypothesis of stationary electrons. In view of the extraordinary power of the theory, it is important to inquire if
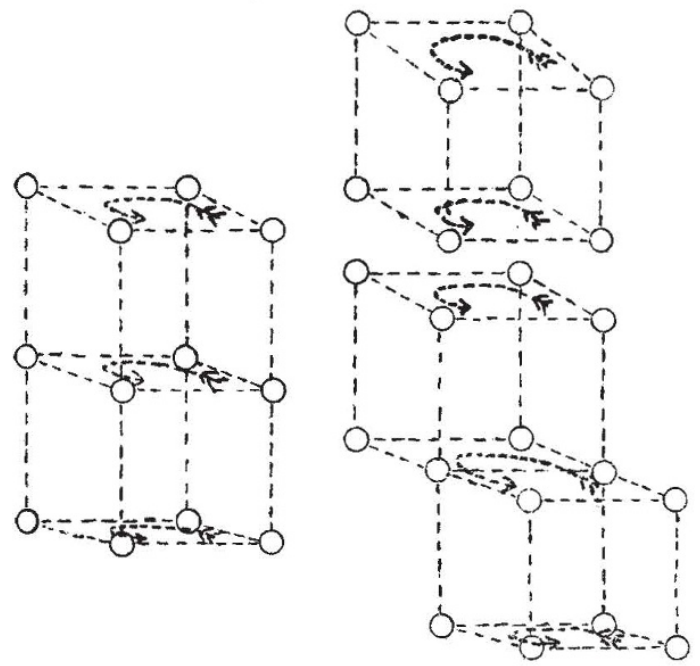

Langmuir's argument from the fixity of direction of the valency forces necessarily holds. There appear to be various ways in which the rotation can be imagined of the stable groups of electrons formed by the combination of atoms. The figures represent diagrammatically, according to Langmuir's system, rotating groups of electrons in the outer shells of molecules of neon, fluorine, and oxygen. In the case of the fluorine molecule the six electrons, forming two quartets with two electrons in common, may revolve as a whole. The same thing may happen in the oxygen molecule, or the electrons may revolve as three quartets. Revolution of the stable groups of electrons would add to the stability of the molecules formed by their combination and increase the directional steadiNO. 2628, VOL. IO5] ness of the valency forces. In this way it may be possible to reconcile Langmuir's theory with that of Bohr. S. C. BRADFORD.

The Science Museum, South Kensington, London, S.W.7, February 16.

\section{Seconding of Officers for Study at Universities.}

THE War Office Memorandum recently issued rightly points with satisfaction to the arrangements made to allow Regular officers to take a full course of study at a university (A.O. 323 of 1919). Unfortunately, however, the conditions under which officers may avail themselves of this privilege are such that only the wealthy ones will be able to take advantage of it, for while seconded they will receive no pay or allowance from Army funds; indeed, it has not even been decided whether the whole or any portion of the period spent at a university will count towards pension.

I venture to suggest that pressure should be brought to bear on the War Office to secure that these privileges shall be open to officers of small means by allowing them to retain their pay and allowances during the time they are undergraduates.

Merchant Venturers' Technical College, J. Wertheimer. Bristol, March 8.

\section{Scientific and Technical Books.}

ONE part of the Descriptive Catalogue of the British Scientific Products Exhibition organised by the British Science Guild last year was devoted to selected lists of books on science and technology.

The guild has been asked to extend these lists, so as to include not only all branches of science, both biological and physical, but also the chief technical subjects. It has undertaken to do this, and a committee, of which I am chairman, has been appointed to prepare such a catalogue.

The lists will be limited to books of British origin actually in current catalogues of the publishers, so that they can be obtained in the usual way through booksellers. School books and elementary manuals will not be included, and the general standard will be that of college courses in scientific and technical subjects or of works libraries. Each list will be submitted to authorities upon the subject with which it deals, but in order to secure that no important work is omitted the committee invites the assistance of everyone interested in its task. Such aid may be afforded by sending (to the British Science Guild, 6 John Street, Adelphi, London, W.C.2) lists or single titles of British books of standard value or proved worth in any branch of science or industry, I shall much appreciate help of this kind which any readers of NATURE may be able to give.

R. A. Gregory.

Davlight Saving and the Length of the Working Day.

Summer time this year is to begin on March 28 and end on September 27 (Nature, February 26, p. 70I). In this connection it may be of interest to point out one effect of the Daylight Saving Act which appears to have escaped notice.

During the six months when the Act is in operation the physiological working day is lengthened by one hour-that is to say, we are all practically compelled to be in active movement (of body or brain) for an hour longer than we normally should be. This lengthened day is accompanied by a curtailment of sleep, particularly in the case of working men who have to rise early, and children. It would be of interest to know the effect of these conditions on the worker's rate of production and the demand for shorter hours.

Hill House, Camberley.
Annie D. Betts. 